\title{
Desempenho térmico de aviário de postura acondicionado naturalmente
}

\section{Thermal performance in layer hen house with natural acclimatization}

\author{
Marco Antônio Martin Biaggioni ${ }^{1}$; Juliana Medeiros de Mattos²; \\ Samir Paulo Jasper ${ }^{3}$; Luiz Antônio Targa ${ }^{4}$
}

\begin{abstract}
Resumo
O objetivo do trabalho foi apresentar análises e comparações sobre o desempenho térmico de um galpão para aves de postura, na região de Bastos, estado de São Paulo, adaptado a partir de alternativas naturais de acondicionamento, tendo como referências um galpão não adaptado, ou seja, de tipologia mais comum na região e outro acondicionado artificialmente. Os parâmetros avaliados - Índice de Temperatura e Umidade (ITU), o Índice de Temperatura de Globo Negro (UTGU), Umidade e a Carga Térmica de Radiação (CTR) - foram calculados a partir de medidas de temperatura de bulbo seco, temperatura de bulbo úmido, temperatura de globo negro e velocidade do ar. As medições foram realizadas, nos ambientes internos e externos, em quatro horários (5, 11, 15 e 16 horas) na estação primavera e verão, durante dez dias consecutivos. Os resultados obtidos permitiram concluir que o sistema de acomodação natural apresentou desempenho intermediário em relação aos demais, possibilitando o controle do ambiente em níveis adequados, somente, durante a primavera.
\end{abstract}

Palavras-chave: Conforto térmico, avicultura, construções rurais

\begin{abstract}
The work aimed at presenting analyses and comparisons of the thermal performance of a laying hens housing in the region of Bastos, in the state of São Paulo, adapted from natural alternatives of acclimatization, having a not adapted housing as reference, that is, of a more common typology in the area, and another one, artificially acclimatized. The index evaluated was the temperature and humidity (THI), the black globe temperature and humidity index (GTHI) and the thermal radiation charge (TRC). It was calculated from the measurement of the temperature of dry bulb, temperature of wet bulb, temperature of black globe and air speed. The measurements were made both in the intern and the extern environment, at four times (5 a.m, 11a.m., 3 p.m. and 4 p.m. o'clock) and in two seasons (late spring and early summer), for ten days in a row. The results allow to conclude that the house naturally acclimatized (NA) has presented intermediate performance as compared with the others, making it to possible to control environment at adequate levels only during spring.
\end{abstract}

Key words: Thermal comfort, poultry, rural building

1 Eng. Agrônomo, Prof. Doutor do Depto. de Engenharia Rural, FCA-UNESP, Campus de Botucatu, Fazenda Experimental Lageado, Botucatu-SP, e-mail: biaggioni@fca.unesp.br

2 Arquiteta, Mestranda PG Energia na Agricultura, Depto. de Engenharia Rural, FCA-UNESP, Campus de Botucatu, Fazenda Experimental Lageado, Botucatu-SP, e-mail: jmarquit@fca.unesp.br

3 Eng. Agrônomo, Doutorando PG Energia na Agricultura, Depto. de Engenharia Rural, FCA-UNESP, Campus de Botucatu, Fazenda Experimental Lageado, Botucatu-SP, e-mail: jasper@fca.unesp.br

4 Eng. Agrônomo, Prof. Doutor do Depto. de Engenharia Rural, FCA-UNESP, Campus de Botucatu, Fazenda Experimental Lageado, Botucatu-SP, e-mail: targa@fca.unesp.br

* Autor para correspondência 


\section{Introdução}

O bem-estar é um dos assuntos mais discutidos atualmente na produção animal. É crescente a convicção dos consumidores de que os animais utilizados para produção de alimentos devem ser bem tratados. As campanhas movidas por diferentes segmentos e a pressão de um número crescente de organizações não-governamentais sensibilizaram a opinião pública em muitos países (principalmente os desenvolvidos) para esse aspecto, o que originou progressos legislativos consideráveis (ALVES; SILVA; PIEDADE, 2007).

Esses estudos tiveram início quando Houghten e Yaglou (1923) propuseram o Índice de Temperatura Efetiva - ITE, baseado na temperatura, umidade e velocidade do ar, usando humanos para comparar sensações térmicas instantâneas, experimentadas em diferentes ambientes.

Do mesmo modo, propuseram-se outros índices, como: o P4SR (Predicted Four Hour Sweat Rate) estimativa da taxa de suor por quatro horas, McArdle et al. (1947); Índice de Estresse Calórico, Belding e Hatch (1955); Índice de Desconforto, mais tarde chamado Índice de Temperatura e Umidade - ITU, Thom (1959); Índice de Humiture, Hevener (1959) e o Índice de Temperatura Aparente, Steadman (1979); contudo, os índices mencionados foram desenvolvidos especificamente para seres humanos. Buffington et al. (1981), trabalhando com vacas leiteiras propuseram, com base no Índice de Temperatura e Umidade, o Índice de Temperatura de Globo Negro e Umidade - ITGU; Rosenberg, Blad e Verma (1983), propuseram o Índice de Temperatura Baixa e Vento - ITBV e, a partir de estudos em câmaras climáticas, Baêta (1985) propôs o Índice de Temperatura Equivalente, para gado de leite.

Segundo Medeiros et al. (2005), desses índices, o mais empregado até a década de 80 para avaliar o ambiente térmico animal, foi o ITU, na década de 90, o ITGU; sabe-se, porém, que a intensidade de participação de cada variável térmica ambiental na composição do índice é diferente para cada espécie animal, em razão de diferenças fisiológicas correspondentes. O ITU e o ITGU podem ser usados para predizer a qualidade de um ambiente térmico para a ave, entretanto com baixa sensibilidade, uma vez que no seu desenvolvimento não se levou em conta a resposta animal.

Pesquisas realizadas com frangos de corte em Belize, por Oliveira e Esmay (1981), mostraram que, para o verão, o aumento nos valores de ITGU de 80 para 82 ocasionou acréscimo de $42 \%$ na conversão alimentar e redução de $37 \%$ no ganho em peso para as aves criadas em área não sombreada, quando comparado com os animais criados em área sombreada. Concluíram os autores que o ITGU foi melhor indicador do conforto térmico que o ITU, e que a diferença entre os índices deveu-se ao efeito da radiação térmica sobre os animais, uma vez que eram idênticas as condições de vento e umidade do ar.

Porém, ainda é grande o desafio, nas condições brasileiras para a definição de um modelo de edificação capaz de proporcionar melhor conforto térmico para os dias quentes e que permita, ainda, um isolamento para que o calor gerado internamente não seja facilmente dissipado para o exterior em dias frios. Essa condição é mais complexa, porque os aviários devem ser versáteis, com elevado poder de adaptação para responder à solicitações opostas: eliminar a radiação solar e ter ventilação abundante no verão; utilizar a radiação solar e controlar severamente a circulação do ar no inverno. Para atender às condições de frio e de calor as instalações devem possuir dispositivos flexíveis que possam controlar o ambiente interno do aviário (ABREU; ABREU, 2001).

Em experimentos para diversas características de instalações e condições climáticas, Teixeira (1983) observou que, na sétima semana de idade das aves, o aumento do índice de ITGU de 74 para 76,7, médias diárias tomadas entre 8 e 16 horas, refletiu em aumento de $41 \%$ na conversão alimentar e em decréscimo de $37,2 \%$ no ganho em peso das aves. 
$\mathrm{Na}$ produção de poedeiras, o meio ambiente é de extrema importância e três fatores se destacam em sua composição: temperatura, umidade relativa e ventilação, sendo que as aves têm exigências diferentes conforme a idade. Assim, temos na fase inicial de cria um período, no qual a ave é exigente em calor. Posteriormente, na fase de postura observa-se uma correlação inversa entre a temperatura e a produtividade, pois a ocorrência de altas temperaturas ambientais irá provocar queda no consumo de ração, pois a ave tenta reduzir metabolismo para diminuir o calor metabólico, com conseqüentes menor produção, menor peso dos ovos e pior qualidade de casca e clara, aumento do consumo de água e também aumentos da temperatura corpórea e da respiração ofegante. Desta maneira, a ave tem que procurar dissipar calor e quanto mais a temperatura ambiente aproxima-se da corporal, maior a dificuldade do sistema orgânico em manter o seu funcionamento (ALBUQUERQUE, 2004).

Diante do exposto, este trabalho teve por objetivo apresentar análises e comparações sobre o desempenho térmico de três sistemas de acomodação (natural, natural alternativo e artificial) para aves de postura, na região de Bastos, estado de São Paulo, nas estações primavera e verão.

\section{Material e Métodos}

O experimento foi desenvolvido em aviários de postura localizados na região da cidade de Bastos, interior do estado de São Paulo, conhecida como a capital nacional do ovo, localizada a $21^{\circ} 55^{\prime} 14^{\prime \prime}$ de latitude (S), 50 44' 07' de longitude (W) e $450 \mathrm{~m}$ de altitude. O clima dessa região, segundo a classificação de Köppen, é Cwa (subtropical). O experimento constou de dois períodos experimentais: primavera e verão. Adotou-se o delineamento de blocos casualizados, em arranjo fatorial $3 \times 4 \times 2$, composto de três sistemas de acomodação (natural, natural alternativo e artificial) e quatro horários de monitoramento da temperatura (5, 11, 15 e 16 horas), cada um com dez repetições, em duas épocas do ano (primavera e verão), totalizando 24 tratamentos.

No sistema de acomodação natural (SAN), sem quaisquer modificações, de dimensões de 100,00 x 3,50 m, construído em madeira, piso de concreto e cobertura com telha de barro, tipo francesa, em duas águas, sem lanternim, com 0,60 m de beiral. A orientação da instalação segue o sentido nortesul, com pé direito de $3,05 \mathrm{~m}$, fechada à altura de 1,00 m com lona no lado oeste, esta sendo de baixo para cima, e tela no lado leste da instalação. As extremidades eram abertas com uma distância de 2,00 m até o início das gaiolas, as quais acomodavam 4,00 a 5,00 aves em cada, totalizando 3,5 mil aves, da linhagem Hisex Brown, com 7 meses de idade.

No sistema de acomodação natural alternativo (SANA) acondicionaram-se aves por métodos naturais, baseado no diagnóstico térmico da região, segundo Perdomo (1999). As alterações foram à pintura do telhado em branco e forro de lona no interior da instalação. Essa de dimensões 100,00 x 3,50 m, construído em madeira, piso de concreto e cobertura com telha de barro, tipo francesa, em duas águas, com lanternim (amianto), com 0,60 m de beiral. A orientação da instalação segue o sentido norte-sul, com pé direito de $2,95 \mathrm{~m}$, fechada à altura de $1,30 \mathrm{~m}$ com lona no lado oeste, esta sendo de baixo para cima, e madeira, com altura $0,80 \mathrm{~m}$ no lado leste da instalação. As extremidades eram fechada em alvenaria de blocos, com uma distância de 3,50 $\mathrm{m}$ até o início das gaiolas, as quais acomodavam 3,00 a 4,00 aves em cada, totalizando 3,5 mil aves, da linhagem Babcock, com 12 meses de idade.

No sistema de acomodação artificial (SAA) com dimensões de 100,00 x 15 m, construído com estrutura de concreto e revestida as extremidades em chapas alumínio, piso de madeira sobre a estrutura de concreto e cobertura em telhado de alumínio, em duas águas, sem lanternim, com $0,60 \mathrm{~m}$ de beiral. A orientação da instalação segue o sentido leste-oeste, com pé direito de $6,00 \mathrm{~m}$, mais altura da cama de 2,20 m, fechado lateralmente com cortinas de lona, abertas automaticamente quando a umidade está 
elevada. As extremidades eram fechadas com chapas de alumínio, apenas dotada de abertura de portas com uma distância de 2,30 m até o início das gaiolas, as quais acomodavam 5,00 a 6,00 aves em cada, totalizando 30 mil aves, da linhagem Hisex White, com 8 meses de idade. As gaiolas eram distribuídas em quatro degraus, o piso era de madeira sobre a estrutura de concreto e a cobertura em telha de alumínio. Foi instalado bem no centro do galpão um sensor de temperatura, o qual fazia com que os umedecedores, localizados ao longo dos quatro corredores, fossem acionados automaticamente quando a temperatura alcançasse $31,5^{\circ} \mathrm{C}$ até que a temperatura reduzisse para $29,5^{\circ} \mathrm{C}$.

Para cálculo dos índices de desempenho térmico foram registrados os seguintes parâmetros: Para obtenção da temperatura do ar, utilizaram-se quatro termômetros de bulbo seco (Tbs) e quatro de bulbo úmido (Tbu), colocados a uma altura de 1,10 $\mathrm{m}$ do piso; sendo que, três deles foram instalados um em cada sistema de acomodação e o quarto instalado no ambiente externo, localizado num ponto eqüidistante aos três sistemas de acomodação, numa altura de 1,50 $\mathrm{m}$ do piso, juntamente foi instalado um anemômetro de fio quente, para registro da velocidade do vento. A umidade relativa foi calculada utilizando-se de uma tabela psicrométrica; Para determinação d temperatura de globo negro (Tgn), utilizaram-se quatro termômetros de globo negro, instalados nos três diferentes sistemas de acomodação e um no ambiente externo, junto com o termômetro de bulbo seco e bulbo úmido.

Com base nesses parâmetros, foi calculado o Índice de Temperatura e Umidade (ITU), citada por Pires et al. (2002), de acordo com a equação 1:

$$
\mathrm{ITU}=0,8 \mathrm{Tbs}+\mathrm{Ur}(\mathrm{Tbs}-14,3) / 100+46,3
$$

Onde:

Tbs - temperatura de bulbo seco $\left({ }^{\circ} \mathrm{C}\right)$,

$\mathrm{Ur}$ - umidade relativa do ar (\%).
O Índice de Temperatura de Globo Negro e Umidade (ITGU), proposto por Buffington et al. (1981), foi obtido de acordo com a equação 2:

$$
\text { ITGU }=\text { Tgn }+0,36 \text { Tpo }-330,08
$$

Onde:

Tgn - temperatura do globo negro (K),

Tpo - temperatura do ponto de orvalho (K).

A Carga Térmica de Radiação (CTR), proposta por Esmay (1979), foi calculada de acordo com a equação 3:

$$
\mathrm{CTR}=\sigma(\mathrm{TRM})
$$

Onde,

CTR - carga térmica de radiação $\left(\mathrm{Wm}^{-2}\right)$, $\sigma-$ constante de Stefan Boltzmann $\left(5,6710^{-8} \mathrm{~K}^{-4}\right)$, TRM - temperatura radiante média $(\mathrm{K})$.

Sendo:

$\mathrm{TRM}=100\left\{2,51 \mathrm{v}^{1 / 2}(\mathrm{Tgn}-\mathrm{Tbs})+(\mathrm{Tgn} / 100)^{4}\right\}^{1 / 4}$

Onde:

$\mathrm{v}$ - velocidade do vento $\left(\mathrm{m} \mathrm{s}^{-1}\right)$,

Tbs - temperatura bulbo seco (K).

\section{Resultados e Discussões}

Temperatura ambiente: Os valores médios de temperatura ambiente, em ${ }^{\circ} \mathrm{C}$, para os diferentes horários, sistemas de acomodação, ambiente externo e épocas do ano, encontram-se relacionados na Tabela 1, na qual se observou que, primeiramente, para ambas as épocas do ano (primavera e verão), no horário das 5 horas, todos os sistemas apresentaram valores mais confortáveis em relação aos demais horários, por ser o período de temperaturas mais amenas do dia. No horário das 11 horas, observaramse que todos os sistemas de acomodação apresentaram valores superiores à $28^{\circ} \mathrm{C}$, em ambas as épocas do ano. Tomando-se como base este valor e segundo as 
recomendações de Baêta e Souza (1997) e Tinoco (2001), pode-se concluir que as aves estavam fora da zona de conforto, mesmo as alojadas no sistema de acomodação artificial (SAA), que demonstrou pouca eficiência no controle da temperatura ambiente para o horário das 11 horas. No horário das 15 horas, um dos mais quentes, a instalação do SAA apresentou temperatura ambiente mais baixa do que os demais, tanto na primavera como verão, provavelmente em função dos equipamentos de acondicionamento; as temperaturas nos sistemas de acomodação natural (SAN) e sistema de acomodação natural alternativo (SANA) ficaram acima da temperatura crítica para as aves poedeiras, a qual, segundo Moura (2001), é por volta de $32^{\circ} \mathrm{C}$.
Esta situação ocorreu durante a época da primavera, ressaltando que a temperatura do ambiente externo, foi menor do que as temperaturas registradas dentro das instalações (SAN e SANA). Justifica-se a elevação da temperatura no interior das instalações ao fato da concentração do número de aves, pois, devido às atividades metabólicas, às mesmas geram calor. Esta diferença de temperatura não foi registrada durante a época do verão. No horário das 16 horas, embora o SAA apresentasse maior eficiência no controle de temperatura (sistema de automação) do que os demais, todos os sistemas de acomodação das aves, registraram temperatura ambiente superior a $28^{\circ} \mathrm{C}$ e, portanto, acima das condições ideais de produção das aves poedeiras.

Tabela 1. Valores médios de temperatura ambiente, em ${ }^{\circ} \mathrm{C}$, obtidos nos diferentes sistemas de acomodação, ambiente externo e diferente horários no período de 10 dias, na estação primavera e verão.

\begin{tabular}{|c|c|c|c|c|}
\hline \multicolumn{5}{|c|}{ Primavera } \\
\hline Sistemas de Acomodação & $5 \mathrm{~h}$ & $11 \mathrm{~h}$ & $15 \mathrm{~h}$ & $16 \mathrm{~h}$ \\
\hline Natural (SAN) & 19,5 & 30,0 & 32,5 & 32,0 \\
\hline Natural Alternativo (SANA) & 19,0 & 30,5 & 32,5 & 31,5 \\
\hline Artificial (SAA) & 20,5 & 29,5 & 30,5 & 30,5 \\
\hline Externo & 18,5 & 29,0 & 31,5 & 31,0 \\
\hline \multicolumn{5}{|c|}{ Verão } \\
\hline Sistemas de Acomodação & $5 \mathrm{~h}$ & $11 \mathrm{~h}$ & $15 \mathrm{~h}$ & $16 \mathrm{~h}$ \\
\hline Natural (SAN) & 23,5 & 30,0 & 31,0 & 31,0 \\
\hline Natural Alternativo (SANA) & 23,5 & 30,5 & 31,5 & 30,0 \\
\hline Artificial (SAA) & 24,5 & 29,0 & 30,5 & 30,0 \\
\hline Externo & 22,5 & 29,0 & 30,0 & 30,0 \\
\hline
\end{tabular}

Umidade relativa do ar: Os valores médios diários da umidade relativa do ar, em porcentagem (\%), para os diferentes sistemas de acomodação, horários, épocas do ano e ambiente externo, encontram-se relacionados na Tabela 2, na qual se observou, primeiramente, para a época da primavera, que no horário das 5 horas, todos os sistemas de acomodação das aves poedeiras, apresentaram umidade relativa do ar considerada acima da zona de conforto térmico que, segundo as recomendações, deve ficar entre 50 e 70\% (BAÊTA; SOUZA, 1997; TINOCO, 2001). Na época da primavera, o
SAA indicou umidade mais elevada, chegando a ultrapassar as recomendações de $80 \%$, citadas por Moura (2001), mostrando que a influência desse sistema de acomodação se estende durante o período noturno, refletindo nos valores de umidade relativa nas primeiras horas da manhã. No horário das 11 horas, o SAA, na primavera, manteve umidade mais elevada que as demais, mas ainda dentro da faixa recomendada pelos autores mencionados; já os outros sistemas de acomodação, apresentaram baixa umidade, ocasionando desconforto e possivelmente, um menor desempenho das aves poedeiras. Nos 
horários das 15 e 16 horas, os valores de umidade foram decrescentes, pois este é o horário em que as temperaturas durante o dia são mais elevadas. O SAA também apresentou umidade relativa abaixo da zona de conforto, na época da primavera.

Durante o verão, às 5 horas, além de todos os sistemas de acomodação apresentaram umidade relativa do ar acima da zona de conforto térmico, verificou-se que todos indicaram valores muito elevados, chegando a ultrapassar as recomendações, de até $80 \%$ (MOURA, 2001). No horário das 11 horas, todos os sistemas de acomodação permaneceram acima da faixa de conforto, com exceção do SANA, que foi o único a entrar na zona de conforto recomendada. A convecção natural, intensificado pela presença do lanternim, possivelmente, foi a principal contribuição para se atingir tais níveis. No horário das 15 e 16 horas, verificou-se que todos os sistemas de acomodação entraram na zona de conforto. Vale destacar, no que diz respeito as condições do clima, que as leituras foram realizadas numa época chuvosa, onde só conseguiu-se um único dia de medição sem chuva torrencial.

Tabela 2. Valores médios da umidade relativa do ar, em (\%), obtidos nos diferentes sistemas de acondicionamentos, e ambiente externo em diferentes horários no período de 10 dias, no período da primavera e verão.

\begin{tabular}{|c|c|c|c|c|}
\hline \multicolumn{5}{|c|}{ Primavera } \\
\hline Sistemas de Acomodação & $5 \mathrm{~h}$ & $11 \mathrm{~h}$ & $15 h$ & $16 \mathrm{~h}$ \\
\hline Natural (SAN) & 76 & 45 & 40 & 39 \\
\hline Natural Alternativo (SANA) & 79 & 44 & 39 & 39 \\
\hline Artificial (SAA) & 85 & 54 & 52 & 49 \\
\hline Externo & 80 & 44 & 37 & 36 \\
\hline \multicolumn{5}{|c|}{ Verão } \\
\hline Sistemas de Acomodação & $5 \mathbf{h}$ & $11 \mathrm{~h}$ & $15 \mathrm{~h}$ & $16 \mathrm{~h}$ \\
\hline Natural (SAN) & 95 & 74 & 65 & 64 \\
\hline Natural Alternativo (SANA) & 87 & 64 & 60 & 60 \\
\hline Artificial (SAA) & 89 & 74 & 67 & 69 \\
\hline Externo & 93 & 73 & 63 & 61 \\
\hline
\end{tabular}

Efeito dos sistemas de acondicionamento sobre os índices de conforto: Os valores médios diários do Índice de Temperatura e Umidade (ITU), Índice de Temperatura de Globo Negro e Umidade (ITGU) e Carga Térmica de Radiação (CTR), nos diversos sistemas de acomodação, estão apresentados na Tabela 3, para ambas as épocas. Para a estação da primavera, apesar dos valores médios dos índices de conforto mostrarem-se dentro da zona de termoneutralidade recomendada - ITU até 78, Armstrong (1994), ITGU até 77, Teixeira (1983), e CTR até 498,3 $\mathrm{Wm}^{-2}$, Rosa (1984), notou-se diferenças significativa entre as médias no ITU entre os três sistemas de acomodação. Observa-se que o
SAA apresentou o ITU mais baixo em relação aos outros dois sistemas; fato ocorrido, possivelmente, porque o SAA, seja dotado de sistema automatizado de resfriamento, amenizando a temperatura de bulbo seco (Tbs). Este sistema de resfriamento permitiu a redução da temperatura e conseqüentemente a elevação da umidade relativa no interior do sistema de acomodação das aves poedeiras. Em relação ao CTR, observou-se uma diferença significativa nos sistemas de acomodação analisados, no qual o SAA apresentou o menor índice de CTR, em relação aos SAN e SANA. Este resultado pode ser explicado pela à orientação do SAA (leste-oeste), enquanto os demais sistemas de acomodação estudos possuíam 
orientação norte-sul, uma vez que, que a radiação solar incidiu nos sistemas de acomodação (SAN e SANA), constantemente ao longo do dia, em relação ao SAA, construído no sentido leste-oeste, no qual ocorreram diferenças na incidência de raios solares, ao longo do dia.

Durante o período do verão, observou-se que não ocorreram variações significativas no ITU para os sistemas de acomodação estudados, porém, registraram-se valores acima da zona de termoneutralidade recomendada, chamando-se a atenção para o valor obtido no $\mathbf{S A N}$, que apresentou maior índice em relação aos demais. A elevada umidade relativa foi, possivelmente, a maior contribuinte para elevação do ITU na época do verão. Considerando o ITGU, verificou-se que não houve diferença estatística em todos os sistemas de acomodação analisadas, porém, os índices médios apresentaram-se acima da zona de conforto, sendo que até um índice de 77 (TEIXEIRA, 1983), não influencia o desempenho das aves poedeiras. Na CTR, também, não foi observado diferenças estatísticas, apenas registrou-se um menor índice médio absoluto para o SAA, devido ao sistema de resfriamento.

Tabela 3. Valores médios de ITU, ITGU e CTR $\mathrm{Wm}^{-2}$ obtidos nos diferentes sistemas de acondicionamento no período de 10 dias na primavera e verão.

\begin{tabular}{|c|c|c|c|}
\hline \multicolumn{4}{|c|}{ Primavera } \\
\hline Sistemas de Acomodação & ITU & ITGU & CTR \\
\hline Natural (SAN) & $75,08 \quad \mathrm{~A}$ & $75,72 \mathrm{~A}$ & $476,51 \quad \mathrm{~A}$ \\
\hline Natural Alternativo (SANA) & $74,89 \quad \mathrm{~A}$ & 75,51 A & $479,21 \quad \mathrm{~A}$ \\
\hline Artificial (SAA) & $65,62 \mathrm{~B}$ & $75,41 \quad \mathrm{~A}$ & $467,95 \quad \mathrm{~B}$ \\
\hline $\mathrm{CV}$ & 1,75 & 1,83 & 3,24 \\
\hline \multicolumn{4}{|c|}{ Verão } \\
\hline Sistemas de Acomodação & ITU & ITGU & CTR \\
\hline Natural (SAN) & $79,40 \quad \mathrm{~A}$ & $77,95 \mathrm{~A}$ & $467,21 \quad \mathrm{~A}$ \\
\hline Natural Alternativo (SANA) & 78,36 A & $77,13 \mathrm{~A}$ & $474,47 \mathrm{~A}$ \\
\hline Artificial (SAA) & $78,83 \mathrm{~A}$ & 77,18 A & $455,64 \mathrm{~A}$ \\
\hline $\mathrm{CV}$ & 2,80 & 4,07 & 8,85 \\
\hline
\end{tabular}

Médias seguidas de letras distintas diferem entre si pelo teste de Tukey ao nível de $5 \%$ de probabilidade.

Efeito do período do dia sobre os índices de conforto: Os valores médios de ITU, ITGU e CTR obtidos nos diferentes horários estão apresentados na Tabela 4. Na primavera, observa-se que o horário das 5 horas mostrou variações significativas para todos os índices de conforto térmico estudados, explicado, pelo fato deste horário registrar as temperaturas mais baixas do dia. No horário das 11 horas, percebeu-se que houve variação dos valores dos índices de conforto térmico em relação ao horário das 5 horas, mesmo assim, todos os índices permaneceram dentro da faixa de conforto, recomendada. Nos horários das 15 e 16 horas, observou-se variação significativa dos índices de conforto térmico em relação aos horários anteriores, mostrando valores de ITU e ITGU que ficaram fora da faixa de termoneutralidade, causando possível desconforto térmico, apenas os valores do CTR permaneceram dentro do limite.

No verão o ITU foi melhor para o horário das 5 horas, fato explicado por neste período ocorreram as menores temperaturas. Para os demais horários o ITU apresentou valores acima da zona de 
termoneutralidade, alcançando maior índice absoluto no horário das 15 horas, mostrando ineficiência nos sistemas de acomodação. O ITGU no horário das 5 horas, também, mostrou-se mais confortável do que os demais horários, notando-se que a partir do horário das 11 horas, todos os valores ficaram fora da zona de conforto, novamente atingindo valores médios absolutos no horário das 15 horas, período em que ocorreram as maiores temperaturas. Para a CTR, o horário das 5 horas mostrou-se mais confortável em relação aos demais. Entretanto, em todos os horários, os valores da CTR se mantiveram na zona de conforto, citado por Rosa (1984), que é de até $498,3 \mathrm{Wm}^{-2}$.

Tabela 4. Valores médios de ITU, ITGU e CTR $\mathrm{Wm}^{-2}$ obtidos nos diferentes horários do dia no período de 10 dias na primavera e verão.

\begin{tabular}{|c|c|c|c|}
\hline \multicolumn{4}{|c|}{ Primavera } \\
\hline Horários (h) & ITU & ITGU & CTR \\
\hline 5 & $66,01 \quad \mathrm{C}$ & $66,84 \quad \mathrm{C}$ & $429,40 \quad B$ \\
\hline 11 & $77,45 \quad$ B & $77,65 \quad \mathrm{~B}$ & $489,27 \quad \mathrm{~A}$ \\
\hline 15 & $79,00 \quad \mathrm{~A}$ & $79,09 \quad \mathrm{~A}$ & $492,16 \quad \mathrm{~A}$ \\
\hline 16 & $78,32 \quad \mathrm{AB}$ & $78,62 \mathrm{~A}$ & $487,36 \quad \mathrm{~A}$ \\
\hline \multicolumn{4}{|c|}{ Verão } \\
\hline Horários (h) & ITU & ITGU & CTR \\
\hline 5 & $73,41 \quad \mathrm{~B}$ & $72,43 \quad \mathrm{~B}$ & $441,18 \quad B$ \\
\hline 11 & $80,62 \mathrm{~A}$ & $77,97 \mathrm{~A}$ & $475,64 \mathrm{~A}$ \\
\hline 15 & $81,10 \mathrm{~A}$ & $79,63 \mathrm{~A}$ & $475,95 \quad \mathrm{~A}$ \\
\hline 16 & $80,31 \quad \mathrm{~A}$ & $79,65 \quad \mathrm{~A}$ & $470,33 \quad \mathrm{~A}$ \\
\hline
\end{tabular}

Médias seguidas de letras distintas, minúsculas nas colunas, diferem entre si pelo teste de Tukey ao nível de 5\% de probabilidade.

Análise das interações sistemas e período do dia para o ITU, ITGU e CTR, durante o período da primavera: Analisando-se interação dos sistemas de acomodação estudados, dentro de cada período do dia, verifica-se pela Tabela 5, que os sistemas de acomodação apresentaram desempenhos significativamente diferentes apenas no horário das 5 horas, pois neste horário no SAA registrou maior ITU comparado com os SAN e SANA. Fato explicado pela condição de isolamento e dimensões do sistema, ou seja, o SAA permaneceu fechado durante a noite, sendo aberto através de cortinas, esporadicamente durante o dia; por sua vez os SAN e SANA são abertos e mais estreitos, fazendo com que o ar seja renovado com mais facilidade, ou seja, maior dependência das condições climáticas externas. Entretanto, no horário das 5 horas, todos os sistemas de acomodação mantiveram-se na zona de conforto (abaixo de 78); por outro lado, a partir das 15 horas, embora não sendo detectada diferença significativa entre os sistemas de acomodação, todos registraram ITU fora da zona de conforto, com a tendência dos SANA e SAA assumirem valores inferiores ao SAN.

Para o ITGU, apenas o SAA apresentou, no horário das 5 horas, valor significativamente mais elevado em relação aos SAN e SANA, embora ambos permaneceram dentro da faixa recomendada. No horário das 11 horas todos os sistemas de acomodação indicaram valores superiores aos recomendados, observando-se que não houve diferença estatística, mostrando-se que o SAA apresentou uma tendência de melhor conforto em relação aos SAN e SANA. Os valores de ITGU atingiram o máximo absoluto no horário das 15 horas, em todos os sistemas de 
acomodação, devido à elevação das temperaturas do globo negro, principalmente das temperaturas do solo aquecido e da superfície inferior da cobertura, que são mais elevadas quando a irradiância solar global também é elevada (ROSA, 1984).

Para o CTR, observou-se que o horário das 5 horas apresentou significativa variação em relação aos demais horários, chamando-se a atenção o valor da CTR obtido para este horário no SANA, o qual apresentou menor valor, provavelmente por filtrar mais a radiação solar durante o dia, mostrando eficiência do sistema de acondicionamento para a CTR nesse horário. Observando-se os valores no horário das 11 horas, notou-se que o valor da CTR no SANA foi muito superior aos demais. Esse pode ser explicado pelo possível erro de leitura do observador, pois o valor apresentado divergiu-se muito em relação aos outros sistemas. Reforçandose essa possibilidade no erro de leitura, percebeuse que os horários das 15 e 16 horas, cujos valores são muito influenciados pelo efeito da radiação, não foram tão altos quanto o valor apresentado no SANA para as 11 horas, indicando-se ainda uma tendência do SAN, ser mais desconfortável, pois apresentou valor mais alto de CTR em relação aos demais sistemas estudados.

Tabela 5. Valores médios de ITU, ITGU e CTR obtidos nos diferentes sistemas de acondicionamentos e horários do dia no período de 10 dias, na estação primavera.

\begin{tabular}{|c|c|c|c|c|}
\hline \multicolumn{5}{|c|}{ ITU } \\
\hline Sistemas de Acomodação & $5 \mathrm{~h}$ & $11 \mathrm{~h}$ & $15 \mathrm{~h}$ & $16 \mathrm{~h}$ \\
\hline Natural (SAN) & 65,46 b C & 75,17 a B & 79,14 a $\mathrm{A}$ & 78,53 a $\mathrm{AB}$ \\
\hline Natural Alternativo (SANA) & 64,93 b C & 77,31 a B & 79,12 a A & 78,22 a $\mathrm{AB}$ \\
\hline Artificial (SAA) & 67,63 a $B$ & 77,88 a A & 78,74 a A & 78,23 a $\mathrm{AB}$ \\
\hline \multicolumn{5}{|c|}{ ITGU } \\
\hline Sistemas de Acomodação & $5 \mathrm{~h}$ & $11 \mathrm{~h}$ & $15 \mathrm{~h}$ & $16 \mathrm{~h}$ \\
\hline Natural (SAN) & 66,27 b C & 77,91 a B & 79,70 a $\mathrm{A}$ & 79,03 a $\mathrm{AB}$ \\
\hline Natural Alternativo (SANA) & 65,74 b C & 77,84 a B & 79,47 ab A & 79,00 a $\mathrm{AB}$ \\
\hline Artificial (SAA) & 68,50 a B & 77,22 a A & 78,10 b A & 77,82 a A \\
\hline \multicolumn{5}{|c|}{ CTR } \\
\hline Sistemas de Acomodação & $5 \mathrm{~h}$ & $11 \mathrm{~h}$ & $15 \mathrm{~h}$ & $16 \mathrm{~h}$ \\
\hline Natural (SAN) & 427,74 a B & 486,57 b A & 499,49 a A & 492,26 b A \\
\hline Natural Alternativo (SANA) & 423,13 a B & 508,34 a $\mathrm{A}$ & 493,56 a A & 491,82 b A \\
\hline Artificial (SAA) & 437,32 a B & $472,90 \quad \mathrm{~b} \mathrm{~A}$ & 483,45 a A & 478,02 b A \\
\hline
\end{tabular}

Médias seguidas de letras distintas, minúsculas nas colunas e maiúsculas nas linhas, diferem entre si pelo teste de Tukey ao nível de $5 \%$ de probabilidade.

Análise das interações sistemas e período do dia para o ITU, ITGU e CTR, durante o período do verão: As médias se encontram na Tabela 6, dos sistemas de acomodação estudados, dentro dos diferentes período do dia, verifica-se, para o ITU que houve variação significativa apenas para o horário das 5 horas, em relação aos demais horários. Contudo, nota-se que nos outros horários do dia o ITU apresentou-se fora da zona de conforto térmico, assim interferindo no rendimento das aves poedeiras.
Destaca-se que não houve diferença estatística entre os sistemas de acomodação nos horários analisados. Notou-se que a partir do horário das 15 horas o SAA passou a apresentar menor índice (ITU), entretanto, permanecendo fora da zona de conforto.

Analisando a Tabela 6, verificaram-se variações do ITGU em relação aos horários estudados, novamente, o horário das 5 horas apresentou os menores valores do índice, porém este horário não registrou diferença significativa entre os sistemas 
de acomodação. Os maiores valores de ITGU começaram a ocorrer a partir das 11 horas, ocorrendo os maiores valores às 15 horas para os SAN e SAA, e às 16 horas para o SANA.

Ainda conforme a Tabela 6 verifica-se que o CTR não apresentou variações significativas entre os horários estudados, ressalta-se, ainda que todos os sistemas de acomodação e horários analisados, o índice se manteve dentro da faixa de conforto térmico. O horário das 16 horas foi o único que apresentou variação significativa entre os sistemas de acomodação, verificou-se um menor valor absoluto para o SAA, isto se pode atribuir ao sistema de resfriamento automatizado.

Tabela 6. Valores médios de ITU, ITGU e CTR obtidos nos diferentes sistemas de acondicionamentos e horários do dia no período de 10 dias, na estação do verão.

\begin{tabular}{|c|c|c|c|c|}
\hline \multicolumn{5}{|c|}{ ITU } \\
\hline Sistemas de Acomodação & $5 \mathrm{~h}$ & $11 \mathrm{~h}$ & $15 \mathrm{~h}$ & $16 \mathrm{~h}$ \\
\hline Natural (SAN) & 72,23 a B & 80,27 a $\mathrm{A}$ & 81,38 a $\mathrm{A}$ & 81,13 a $\mathrm{A}$ \\
\hline Natural Acondicionado (SANA) & 72,65 a B & 80,27 a A & 81,07 a A & 79,44 a A \\
\hline Artificial (SAA) & 74,31 a B & 79,80 a $\mathrm{A}$ & 80,83 a A & 80,36 a A \\
\hline \multicolumn{5}{|c|}{ ITGU } \\
\hline Sistemas de Acomodação & $5 \mathrm{~h}$ & $11 \mathrm{~h}$ & $15 \mathrm{~h}$ & $16 \mathrm{~h}$ \\
\hline Natural (SAN) & 72,23 a B & 79,81 a $\mathrm{A}$ & 79,96 a $\mathrm{A}$ & 79,79 a A \\
\hline Natural Acondicionado (SANA) & 72,06 a C & 76,27 b B & 79,98 a A & 80,21 a A \\
\hline Artificial (SAA) & 73,00 a B & $77,83 \mathrm{ab} \mathrm{A}$ & 78,97 a A & 78,93 a A \\
\hline \multicolumn{5}{|c|}{ CTR } \\
\hline Sistemas de Acomodação & $5 \mathrm{~h}$ & $11 \mathrm{~h}$ & $15 \mathrm{~h}$ & $16 \mathrm{~h}$ \\
\hline Natural (SAN) & 436,58 a A & 477,61 a A & 476,67 a A & 477,99 ab A \\
\hline Natural Acondicionado (SANA) & 443,86 a A & 484,42 a $\mathrm{A}$ & 480,97 a A & 488,63 a A \\
\hline Artificial (SAA) & 443,09 a A & 464,90 a A & 470,21 a A & 444,36 a A \\
\hline
\end{tabular}

Médias seguidas de letras distintas, minúsculas nas colunas e maiúsculas nas linhas, diferem entre si pelo teste de Tukey ao nível de $5 \%$ de probabilidade.

\section{Conclusões}

Baseando-se nos resultados obtidos nas condições deste trabalho, chegou-se as seguintes conclusões principais: 1) O galpão com melhor desempenho foi o artificial e o mais insatisfatório foi o galpão natural; 2) Horário das 15 horas foi o período do dia mais crítico, trazendo desconforto em todos os sistemas; 3) Os sistemas de acondicionamento estudados permitiram atingir condições de conforto térmico apenas na estação primavera.

\section{Referências}

ABREU, V. M. N.; ABREU, P. G. Diagnóstico bioclimático: qual sua importância na produção de aves? Avicultura Industrial, Porto Feliz, v. 91, n. 9, p. 16-20, 2001.

ALBUQUERQUE, R. Tópicos importantes na produção de poedeiras comerciais. Avicultura Industrial, Porto Feliz, v. 95, n. 3, p. 53-56, 2004.

ALVES, S. P.; SILVA, I. J. O.; PIEDADE, S. M. S. Avaliação do bem-estar de aves poedeiras comerciais: efeitos do sistema de criação e do ambiente bioclimático sobre o desempenho das aves e a qualidade de ovos. Revista Brasileira de Zootecnia, Viçosa, v. 26, n. 5, p. 1388-1394, 2007. 
ARMSTRONG, D. V. Heat stress interaction with shade and cooling. Journal of Dairy Science, Champaign, v. 77, n. 7, p. 2044-2050, 1994.

BAÊTA, F. C. Responses of lactating dairy cows to the combined effects of temperature, humidity and wind velocity in the warn season. 1985. Thesis. (Ph.D) University of Missouri, Columbia.

BAÊTA, F. C.; SOUZA, C. F. Ambiência em edificações rurais: conforto térmico animal. Viçosa: Ed. da UFV, 1997.

BELDING, H. S.; HATCH, T. F. Index for evaluating heat stress in terms of resulting physiological strain. Heating, Piping and Air Conditioning, Cleaveland, v. 3, n. 27, p. 129-136, 1955.

BUFFINGTON, D. E.; COLLASSO-AROCHO, A.; CANTON, G. H.; PITT, D. Black globe-humidity index (BGHI) as comfort equation for dairy cows. Transaction of the ASAE, Saint Joseph, v. 24, n. 3, p. 711-714, 1981.

ESMAY, M. L. Principles of animal environment. West Port: AVI Publishing, 1979.

HEVENER, O. F. All about humiture. Weatherwise, Washington, v.12, n.5, p.83-85, 1959.

HOUGHTEN, F. C.; YAGLOU, C. P. Determining lines of equal comfort. ASHVE Transaction, Saint Joseph, v. 29, n. 4, p. 163-176, 1923.

MCARDLE, B.; DUNHAM, W.; HOLLING, H. E.; LADELL, W. S. S.; SCOTT, J. W.; THOMSON, M. L.; WEINER, J. S. The prediction of the physiological effects of warm and hot environments: the P4SR index. London: Medical Research Council, 1947.

MEDEIROS, C. M.; BAÊTA, F. C.; OLIVEIRA, R. F. M.; TINÔCO, I. F. F.; ALBINO, L. F. T.; CECON, P. R. Índice térmico ambiental de produtividade para frangos de corte. Revista Brasileira de Engenharia Agrícola e Ambiental, Campina Grande, v. 9, n. 4, p. 660-665, 2005.

MOURA, D. J. Ambiência na avicultura de corte. In: SILVA, I. J. O. Ambiência na produção de aves em clima tropical. Piracicaba: FUNEP, 2001. p. 81-93.
OLIVEIRA, J. L.; ESMAY, M. L. Systems model analysys of hot weather housing for livestock. American Society of Agricultural Engineers, Saint Joseph, p. 1-17, 1981. Paper 81-4561.

PERDOMO, C. C. Projetos para construções rurais e ambiência. In: CONGRESSO BRASILEIRO DE ENGENHARIAAGRÍCOLA, 28., 1999, Pelotas. Anais... Pelotas: Ed. da UFPel, 1999. CD-ROM.

PIRES, M. F. A.; FERREIRA, A. M.; SATURNINO, H. M.; TEODORO, R. L. Taxa de gestação em fêmeas da raça Holandesa confinadas em free stall, no verão e inverno. Arquivo Brasileiro de Medicina Veterinária e Zootecnia, Belo Horizonte, v. 54, n. 1, p. 1-10, 2002.

ROSA, Y. B. C. J. Influência de três materiais de cobertura no indice de conforto térmico, em condições de verão para Viçosa, MG. 1984. Dissertação (Mestrado em Agronomia - Energia na Agricultura) - Universidade Federal de Viçosa, Viçosa.

ROSENBERG, N. J.; BLAD, B. L.; VERMA, S. B. Microclimate: the biological environment. New York: Wiley-Interscience Publication, 1983.

STEADMAN, R.G. The assessment of sultriness. Part I: A temperature-humidity index based on human physiology and clothing science. Journal of Applied Meteorology, Boston, v. 18, n.7, p.861-873, 1979.

TEIXEIRA, V. H. Estudo dos índices de conforto em duas instalações de frango de corte para as regiões de Viçosa e Visconde de Rio Branco, MG. 1983. Dissertação (Mestrado em Engenharia Agrícola) - Universidade Federal de Viçosa, Viçosa.

THOM, E. C. The discomfort index. Weatherwise, Washington, v. 12, n. 2, p. 57-60, 1959.

TINOCO, I. F. F. Avicultura industrial: novos conceitos de materiais, concepções e técnicas construtivas disponíveis para galpões avícolas brasileiros. Revista Brasileira de Ciência Avícola, Campinas, v. 3, n. 1, p. 1-26, jan./abr. 2001. 
